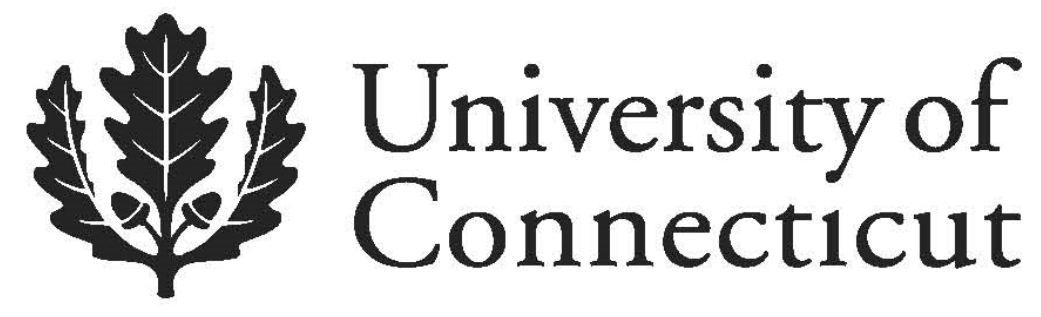

Department of Economics Working Paper Series

\title{
The Co-Movement and Causality between the U.S. Real Estate and Stock Markets in the Time and Frequency Domains
}

\author{
Tsangyao Chang \\ Feng Chia University \\ Xiao-lin Li \\ Wuhan University \\ Stephen M. Miller \\ University of Nevada, Las Vegas \\ University of Connecticut \\ Mehmet Balcilar \\ Eastern Mediterranean University \\ Rangan Gupta \\ University of Pretoria
}

Working Paper 2013-34

December 2013

365 Fairfield Way, Unit 1063

Storrs, CT 06269-1063

Phone: (860) 486-3022

Fax: (860) 486-4463

http://www.econ.uconn.edu/

This working paper is indexed on RePEc, http://repec.org 


\title{
The Co-Movement and Causality between the U.S. Real Estate and Stock Markets in the Time and Frequency Domains
}

\author{
Tsangyao Chang ${ }^{\mathrm{a}}$, Xiao-lin Li ${ }^{\mathrm{b}}$, Stephen M. Miller ${ }^{\mathrm{c}}$, \\ Mehmet Balcilar ${ }^{\mathrm{d}}$ and Rangan Gupta ${ }^{\mathrm{e}}$
}

\begin{abstract}
This study applies wavelet analysis to examine the relationship between the U.S. real estate and stock markets over the period 1890-2012. Wavelet analysis allows the simultaneous examination of co-movement and causality between the two markets in both the time and frequency domains. Our findings provide robust evidence that co-movement and causality vary across frequencies and evolve with time. Examining market co-movement in the time domain, the two markets exhibit positive co-movement over recent past decades, exception for 1998-2002 when a high negative co-movement emerged. In the frequency domain, the two markets correlate with each other mainly at low frequencies (longer term), except in the second half of the 1900s as well as in 1998-2002, when the two markets correlate at high frequencies (shorter term). In addition, we find that the causal effects between the markets in the frequency domain occur generally at low frequencies (longer term). In the time-domain, the time-varying nature of long-run causalities implies structural changes in the two markets. These findings provide a more complete picture of the relationship between the U.S. real estate and stock markets over time and frequency, offering important implications for policymakers and practitioners.
\end{abstract}

Key words: stock market; real estate market; wavelet analysis; frequency domain; time domain

JEL: $\quad$ C49, E44, G11

\footnotetext{
${ }^{a}$ Department of Finance, Feng Chia University, Taichung, Taiwan. Email: tychang@fcu.edu.tw.

b Department of Finance, School of Economics and Management, Wuhan University, Wuhan, China. Email: smileman2004@126.com.

c Corresponding author. Department of Economics, University of Nevada, Las Vegas, Las Vegas, Nevada, 89154-6005 USA, Email: stephen.miller@unlv.edu.

d Department of Economics, Eastern Mediterranean University, Famagusta, Turkish Republic of Northern Cyprus, via Mersin 10, Turkey. Email: mehmet@mbalcilar.net.

e Department of Economics, University of Pretoria, Pretoria, 0002, South Africa. Email: rangan.gupta@up.ac.za.
} 


\section{Introduction}

This paper provides some fresh insights on the links between the U.S. real estate and stock markets. In the U.S. economy, real estate and stock holdings comprise the two largest and principal components of wealth. Movements in their market values can dramatically affect the economic condition of families and business and, hence, affect the overall growth of the U.S. economy. Booms and busts in real estate and stock markets have always played an important role in U.S. business cycle history. The most recent financial crisis and Great Recession saw a great housing bubble burst followed by a remarkable stock market crash, causing the U.S. and the world economy to suffer huge financial losses. Since stocks act as one of the most convenient investment vehicles with low transaction cost and high liquidity while real estate acts as a 'bulky' asset with high transaction cost and low liquidity, the two assets typically appear in homebuyers' and investors’ portfolios (Lin and Fuerst, 2012). The diversification benefits, however, hinge on the relationships between the two underlying markets. This paper identifies co-movements and causality in the time and frequency domains between these two markets in the U.S., using distinctive methods and data and deriving new insights and implications for investment strategies and market forecasts.

The recent research on the relationships between real estate and stock markets falls into three main strands. First, researchers employ linear and non-linear cointegration techniques, such as Johansen, fractional, and threshold cointegration tests, to determine whether the two markets are integrated or segmented (Ambrose et al., 1992; Wilson and Okunev, 1999; Liow, 2006; Lin and Fuerst, 2012; Liow and Yang, 2005; Tsai et al., 2012). The identification of markets as integrated or segmented in an economy is pivotal for practitioners and policymakers. Market integration means that a high degree of asset substitution exists between real estate and equities, while market segmentation implies the two assets provide good risk diversifiers for each other in portfolio management (Wilson et 
al., 1996).

Second, researchers consider the causal links between real estate and stock markets by applying causality tests in vector autoregressive (VAR), vector error-correction (VEC), and threshold error-correction models (TECM) (Gyourko and Keim, 1992; Okunev et al., 2000; Sim and Chang, 2006; Su, 2011; Su et al., 2011; McMillan, 2012; Shirvani et al., 2012; Tsai et al., 2012). The nature and direction of causality between the two markets can aid policymakers and investors to forecast future performance from one market to the other through two transmission mechanisms (Chen, 2001; Case et al., 2005; Kapopoulos and Siokis, 2005). One, the "wealth effect" indicates that a rise in stock prices and, hence, an unexpected gain in stock returns can boost real estate consumption and prices, while two, the “credit-price effect” suggests that a rise in real estate prices can, in turn, lead to an increase in stock market prices.

Third, researchers in earlier studies concentrate on the correlation between real estate and stock markets through standard correlation analysis (Ibbotson and Siegel, 1984; Hartzell, 1986; Eichholtz and Hartzell, 1996; Worzala and Vandell, 1993; Quan and Titman, 1999). Correlation analysis interprets co-movement between the markets, which can suggest assets diversification benefits for investors.

These existing studies exclusively utilize the conventional time-domain methods, namely the above-mentioned cointegration techniques, causality tests, and correlation analysis with the exception of Liow (2012) who adopts dynamic conditional correlation (DCC) models to assess time-varying co-movement between the real estate and stock markets. ${ }^{1}$ That is, the existing literature typically ignore any the time-variation in the

\footnotetext{
${ }^{1}$ Following the extant literature, we, too, run standard linear Granger causality tests in a VAR model of the real rates of return for house and stock prices, which Table A1 indicates are stationary, $I(0)$, variables. Table A2 reports that the causality tests do not reject the null of no-causal relationship between the two variables. Further, we also test for cointegration between the natural logarithm of the real house and stock prices, which are nonstationary, I(1), variables. Table A3 shows that we cannot reject the null hypothesis of no-cointegration. Moreover, Table A4 reports evidence of instability of the long-run relationship estimated using fully-modified
} 
relationships between the two markets. Moreover, these studies do not explore the frequency-variation in such relationships by these time-domain approaches. Nevertheless, the time- and frequency-varying features in such relationships can provide important practical implications for portfolio management. Time-varying co-movement implies that the risk exposure and diversification benefits of asset portfolios evolve over time and, thus, investors should incorporate such effects when evaluating the risk and returns of these portfolios. Frequency-varying co-movement suggests that investors with different investment horizons should consider the co-movement at corresponding frequencies so as to allocate their assets more effectively. The time- and frequency-varying features in the causality can also significantly affect the accuracy of market performance prediction and, hence, affect the investment benefits for practitioners and the regulatory benefits to policymakers. A recent study by Zhou (2010) stresses the importance of the time- and frequency-variation in the assessment of the relationship between the two markets.

This paper utilizes a novel wavelet analysis to explore the real relationship between the U.S. real estate and stock markets in both the time and frequency domains. Wavelet analysis possesses significant advantages over conventional time-domain methods. It expands the underlying time series into a time-frequency space where researches can visualize both time- and frequency-varying information of the series in a highly intuitive way. Wavelet coherency and phase differences simultaneously assess how the co-movement and causalities between the U.S. real estate and stock markets vary across frequencies and change over time in a time-frequency window. In this way, we can observe high-frequency (short-term) and low-frequency (long-term) relationships between the two markets as well as possible structural changes and time-variations in such relationship. Goffe (1994) and Ramsey and

ordinary least squares method. Hence, the lack of causality does not reflect misspecification of the VAR in first-differences (growth rates) of the variables. Finally, Table A5 provides strong evidence of structural breaks in the individual equations of the VAR model, as well as the VAR model as a system, thus, invalidating the full-sample Granger causality result reported in Table A1. This, in turn, motivates the need for a time-varying approach to causality, which the wavelet analysis provides. 
Lampart (1998a, b) introduced applications of wavelet analysis in economics and finance. More recent work, however, focuses on the co-movement between stock markets as well as between energy commodities and macroeconomy (Rua and Nunes, 2009; Graham and Nikkinen, 2011; Aguiar-Conraria and Soares, 2011; McCarthy and Orlov, 2012; Loh, 2013; etc.). To the best of our knowledge, limited work so far applies wavelet analysis to the relationship between real estate and stock markets with the exception of Zhou (2010) who assesses the co-movement between the two markets for six countries. He considers, however, only the co-movement between the securitized real estate and stock markets and the U.S. case receives partial attention, which motivates our analysis.

This study contributes to the existing literature in several important ways. First, the wavelet analysis devotes special and full attention to dynamic co-movement and causalities between the U.S. real estate and stock markets. Second, we use the distinctive annual data of Robert Shiller's housing and S\&P stock returns over an extended from 1890 to 2012, which implies that our findings apply for practitioners and policymakers in the residential real estate and stock markets. Third, we employ the growth rate of GDP as a control variable to reveal the true relationships between the two markets by removing the effects of economic growth on both the real estate and stock markets performances (Quan and Titman, 1999). Fourth, we also estimate the partial wavelet coherency and partial phase difference as necessary complements to the common-used wavelet coherency and phase difference. Finally, we perform a simultaneous assessment of the co-movement and causal relationships between the two markets in the time and frequency domains.

Our empirical results show substantial time- and frequency-varying features in the co-movement and causality between the U.S. real estate and stock markets. This provides additional and useful implications for investment strategies and the forecasts of the markets' performance for investors and policymakers. In addition, we identify the co-movement during 
the recent financial crisis with the results showing that the two markets actually respond more to economic growth fundamentals, rather than to each other.

This paper proceeds as follows. Section 2 briefly reviews the related literature. Section 3 provides an overview of wavelet theory and methods. Section 4 describes the data and presents the empirical results. Section 5 concludes.

\section{Literature Review}

As mentioned above, a large literature exists to identify whether real estate and stock markets are integrated or segmented through a variety of cointegration techniques. The results differ widely depending on the datasets examined and the methodology used. Liu et al. (1990) adopt the capital asset pricing model (CAPM) presented by Jorion and Schwartz (1986) and find that segmentation does exist between the U.S. real estate and stock markets because of indirect barriers such as the cost, amount, and quality of information on real estate. Geltner (1990) supports this segmentation hypothesis by documenting that the noise component of real estate differs from the noise component of stock returns. Ambrose et al. (1992) conclude on the contrary, however, that the securitized real estate market may integrate with the stock market, using a rescaled range analysis to test deterministic nonlinear trend in the underlying return series. Meyer and Webb (1993) also report a certain degree of integration between the two markets, noting that the returns on equity Real Estate Investment Trusts (REITs) seem similar to the returns on common stocks. Liow (2006) finds that the stock (including property stock) market integrates with the real estate market in the Singapore economy, using the autoregressive distributed lag (ARDL) cointegration procedure.

Okunev and Wilson (1997) develop a fractional cointegration test, which considers a stochastic trend term instead of the deterministic drift term employed by Ambrose et al. (1992). They conclude that the U.S. real estate and stock markets are fractionally integrated. Following their analysis, the literature widely employs the non-linear fractional cointegration 
test. Wilson and Okunev (1999) apply this technique to test for long-term relationship between the securitized real estate and stock markets for three countries, finding segmented markets in the U.S. and the U.K., but somewhat integrated markets in Australia. Lin and Fuerst (2012) apply both the fractional and Johansen’s $(1988,1991)$ cointegration tests, demonstrating that the stock market linearly integrates with direct real estate market (securitized real estate market) in China, Japan and Thailand, but fractionally integrates in Singapore and Hong Kong, and remains segmented in Taiwan, Malaysia, Indonesia and South Korea. In an earlier study, Liow and Yang (2005) infer from the same fractional cointegration analysis that the securitized real estate (indirect real estate) and stock markets in Singapore and Hong Kong are fractionally integrated and, thus, the two underlying assets substitute over the long term. Additionally, Tsai et al. (2012) use the momentum-threshold autoregressive (M-TAR) method and find an asymmetric cointegration relationship between the U.S. housing and stock markets.

A growing number of studies consider the causal link between the real estate and stock markets. Gyourko and Keim (1992) suggest a causal link from the U.S. stock market to real estate market by testing on the S\&P 500 and equity REITs return series. Okunev et al. (2000) detect a strong unidirectional causality running from the U.S. stock market to the real estate market by employing nonlinear causality tests. Su (2011) conducts the non-linear causality tests based upon the TECM and provides evidence in favor of the credit-price effect in Germany, the Netherlands, and the U.K., the wealth effect in Belgium and Italy, and both effects in France, Spain, and Switzerland. Ibrahim (2010) confirms the wealth effect channel for Thailand, using standard linear Granger causality tests. Tsai et al. (2012) also perform the similar non-linear causality test in the context of TECM, concluding that the wealth effect dominates when the U.S. stock market outperforms the housing market. McMillan (2012) adopts another exponential smooth transition (ESTR) procedure for non-linear causality test, 
finding a unidirectional causality running from real estate prices to stock prices in the U.S. and the U.K., which implies a credit-price effect across the two economies. Shirvani et al. (2012) report the presence of bilateral causality between the U.S. stock prices and residential real estate prices. Kapopoulos and Siokis (2005) support the wealth effect hypothesis for Athens real estate prices but not for other Greek urban real estate prices. Sim and Chang (2006) provide evidence that most Korean regional housing and land markets Granger cause stock prices in a VAR framework, which supports the credit-price hypothesis. Bouchouicha (2013) constructs non-linear Markov switching models to assess the causal link between the real estate and stock markets in the U.S. and the U.K. with the maximum likelihood (ML) estimations indicating that credit-price effect is stronger than wealth effect in both countries. Along similar lines, Aye et al. (2013), based on nonparametric tests, find that not only does the real house price cointegrate with the real stock price, but also bi-directional causality exists between these two asset prices, even when standard linear cointegration and Granger causality tests fail to pick up any relationship between these two asset prices.

In addition, from the time-domain, earlier studies investigate the correlation between real estate and stock markets. Ibbotson and Siegel (1984), Hartzell (1986), and Eichholtz and Hartzell (1996) show a negative correlation between the two markets for the U.S., the U.K., and Canada, whereas Worzala and Vandell (1993) find a positive correlation between the U.K. real estate and stock markets. Quan and Titman (1999) support the positive correlation between the two markets by estimating cross-sectional data from seventeen different countries. More recently, Liow (2012) assesses the time-varying co-movement between the two markets using the dynamic conditional correlation (DCC) method, but neglects the frequency-varying features in markets co-movement.

While the existing literature generally adopts time-domain analysis, Zhou (2010), the closest study to our analysis, uses wavelet analysis to evaluate the co-movement between six 
global securitized real estate markets -the U.S., the U.K., Japan, Australia, Hong Kong, and Singapore as well as the co-movement between the securitized real estate and stock markets of the same country. The results indicate strong co-movement across a large range of frequencies for Japan, Hong Kong, and Singapore, but only across a limited band of frequencies for the U.S., the U.K. and Australia.

Our paper differs from Zhou (2010) by concentrating on the time- and frequency-varying features of both the co-movement and causalities between the U.S. real estate and stock markets, instead of just analyzing their co-movement. Moreover, we employ the annual transaction-based Shiller housing returns and S\&P stock returns data from 1890 to 2012. Lastly, we use the growth rate of GDP to control for the general economy's effect, attempting to extract the direct real relationships between the two markets.

\section{Wavelet Theory and Methods}

Wavelet analysis originated in the mid-1980s as an alternative to the well-known Fourier analysis. Though Fourier analysis can uncover how relations vary across frequencies using spectral techniques, the Fourier-tranform analysis discards the time-localized information. Moreover, Fourier analysis is merely suitable for stationary series. In contrast, wavelet analysis conducts the estimation of spectral characteristics of a time series as a function of time (Aguiar-Conraria et al., 2008). It, therefore, can extract localized information in both time and frequency domains. Moreover, wavelet analysis exhibits a significant advantage over Fourier analysis for non-stationary or locally stationary series (Roueff and Sachs, 2011).

\subsection{Continuous wavelet transform}

The wavelet transform decomposes a time series into some basis wavelets, which are stretched and translated versions of a given mother wavelet localized in both the time and frequency domains. In this way, the series expands into a time-frequency space where its oscillations appear in a highly intuitive way. Often, two kinds of wavelet transforms exist: 
discrete wavelet transforms (DWT) and continuous wavelet transforms (CWT). The former reduces noise and compresses data whereas the latter extracts features and detects data self-similarities (Grinsted et al., 2004; Loh, 2013). ${ }^{2}$ In this paper, we choose the CWT to decompose the concerned series into wavelets.

The CWT of a given time series $x(t)$ is defined as a convolution type:

$$
W_{x}(\tau, s)=\int_{-\infty}^{+\infty} x(t) \psi_{\tau, s}^{*}(t) d t
$$

where the asterisk indicates the complex conjugation and $\psi_{\tau, s}{ }^{*}(t)$ is the complex conjugate function of $\psi_{\tau, s}(t)$, namely, the basis wavelet function. As mentioned, the basis wavelet comes from a given mother wavelet, represented by $\psi(t)$ in the sense that:

$$
\psi_{\tau, s}(t)=\frac{1}{\sqrt{s}} \psi\left(\frac{t-\tau}{s}\right)
$$

where $s$ is the wavelet scale that controls how the mother wavelet is stretched, and $\tau$ is the location parameter that controls where the wavelet is centered. By changing the scale parameter ( $s$ ) and translating along the localized time index $(\tau)$, one can construct a picture showing how the amplitudes of $x(t)$ vary across scale and over time (Torrence and Compo, 1998).

A mother wavelet of the CWT must fulfill three conditions. First, the mean must equal zero, that is, $\int_{-\infty}^{+\infty} \psi(t) d t=0$, which ensures it that it oscillates across positive and negative values and, thus, is nonzero locally. Second, its square must integrate to unity, that is,

\footnotetext{
${ }^{2}$ Feature extraction simplifies the resources required to describe a large set of data accurately. If we carefully choose the features to extract, then the features set will provide the relevant information from the input data to perform the desired task, using this reduced representation instead of the full-sized input. The self-similarity of a time series means the series exhibits long-term dependence (i.e., the whole series possesses the same shape, such as wave and cycle, as one or more of its parts). Taking advantage of feature extraction and self-similarity detection, the CWT extracts the local amplitudes of a time series (e.g., business cycle series) in time and frequency domains. Then, the ensuing wavelet coherency and phase difference tools measure whether and how the local amplitudes of two time series correlate, and which one leads.
} 
$\int_{-\infty}^{+\infty} \psi^{2}(t) d t=1$, which implies a limitation to an interval of time. Finally, it must satisfy the admissibility condition, which means that:

$$
0 \prec C_{\varphi}=\int_{0}^{+\infty} \frac{|\widehat{\psi}(\omega)|^{2}}{\omega} d \omega \prec+\infty,
$$

where $\hat{\psi}(\omega)$ is the Fourier transform of the mother wavelet $\psi(t)$. In wavelet theory and practice, various types of mother wavelets exist for various purposes, such as the Haar, Morlet, Daubechies, Mexican hat and so on wavelets. Among them, the most popular and applicable mother wavelet for feature extraction is the Morlet wavelet, which Grossman and Morlet (1984) introduce. It is as follows:

$$
\psi(t)=\pi^{-1 / 4} e^{i \omega_{0} t} e^{-\omega_{0}^{2} / 2},
$$

where $\pi^{-1 / 4}$ ensures its unity energy (i.e., $\int_{-\infty}^{+\infty} \psi^{2}(t) d t=1$ ) and $e^{-\omega_{0}^{2} / 2}$ ensures that it satisfies the admissibility condition of equation (3). In particular, when the dimensionless frequency $\omega_{0}$ equals 6 , the Morlet wavelet achieves optimal trade-off between time and frequency localization (Grinsted et al., 2004). According to Aguiar-Conraria and Soares (2013), the Fourier frequency $f$ is given by $f(s)=\omega_{0} / 2 \pi s$. Therefore, for the best choice of $\omega_{0}=6$, the conversion from the wavelet scale $s$ to the Fourier frequency $f$ occurs in the sense that:

$$
f=6 / 2 \pi s \approx 1 / s
$$

As a result, the wavelet scale approximates a reciprocal of the Fourier frequency, which implies that $x(t)$ decomposes into a joint time-frequency plane where the shorter (longer) wavelet scale corresponds to the higher (lower) frequency. Moreover, since the Morlet wavelet is a complex wavelet, the CWT divides into real and imaginary parts. As such, we can calculate the amplitudes and phases of the CWT for further estimations of wavelet 
power spectrum, wavelet coherency and phase difference.

\subsection{Wavelet power spectrum}

In wavelet theory and practice, the wavelet power spectrum of one series $x(t)$, namely the auto-wavelet power spectrum, is simply defined as $\left|W_{x}(\tau, s)\right|^{2}$. It presents a measure of the localized variance, that is, the localized volatility of $x(t)$ at each scale or frequency. Furthermore, since Hudgins et al. (1993) first introduce the cross-wavelet transform of $x(t)$ and $y(t)$ as $W_{x y}(\tau, s)=W_{x}(\tau, s) W_{y}^{*}(\tau, s)$, the cross-wavelet power spectrum is accordingly written as:

$$
\left|W_{x y}(\tau, s)\right|^{2}=\left|W_{x}(\tau, s)\right|^{2}\left|W_{y}^{*}(\tau, s)\right|^{2}
$$

where the asterisk indicates the complex conjugation. The cross-wavelet power spectrum can give a measure of the localized covariance between $x(t)$ and $y(t)$ for the specified frequency.

In this paper, the wavelet power spectrum depicts the localized volatility of the U.S. real estate and stock markets as well as estimates the wavelet coherency between the two markets. Note that, in wavelet power spectrum plots, the wavelet power of real estate and stock series is marked by color bars on the right side, where red colors correspond to high power while blue colors correspond to low power. That is, the color bars also correspond to the localized volatility of the underlying series.

\subsection{Wavelet coherency and phase difference}

Wavelet coherency allows for a three-dimensional analysis, which simultaneously considers the time and frequency components, as well as the strength of correlation between the time-series components (Loh, 2013). In this way, we can observe both the time- and frequency-variations of the correlation between series in a time-frequency space. 
Consequently, the wavelet coherency provides a much better measure of co-movement between the U.S. real estate and stock markets in comparison to the conventional correlation analysis as well as the dynamic conditional correlation analysis (Zhou, 2010; Liow, 2012; Loh, 2013). Following the approach of Torrence and Webster (1999), we estimate wavelet coherency by using the cross-wavelet and auto-wavelet power spectrums in the sense that:

$$
R_{x y}^{2}(\tau, s)=\frac{\left|S\left(s^{-1} W_{x y}(\tau, s)\right)\right|^{2}}{S\left(s^{-1}\left|W_{x}(\tau, s)\right|^{2}\right) S\left(s^{-1}\left|W_{y}(\tau, x)\right|^{2}\right)} .
$$

Here, we calculate wavelet coherency with the above squared type and the smoothing operator $S^{3}$. In this way, it gives a quantity between 0 and 1 in a time-frequency window. Zero coherency indicates no co-movement between real estate and stock markets while the highest coherency implies the strongest co-movement between the two markets. In the empirical section, we also clearly mark the squared wavelet coherency with color bars on the right-hand side of the wavelet coherency plots, where red colors correspond to a strong co-movement whereas blue colors correspond to a weak co-movement.

Because the wavelet coherency is squared, we cannot distinguish between positive and negative co-movements. Therefore, we subsequently use the phase difference to provide information on positive and negative co-movements as well as the lead-lag relationships between the two markets. According to Bloomfield et al. (2004), the phase difference characterizes phase relationship between $x(t)$ and $y(t)$ such that:

$$
\phi_{x y}=\tan ^{-1}\left(\frac{\mathfrak{J}\left\{S\left(s^{-1} W_{x y}(\tau, s)\right)\right\}}{\mathfrak{R}\left\{S\left(s^{-1} W_{x y}(\tau, s)\right)\right\}}\right) \text {, with } \phi_{x y} \in\left[\begin{array}{ll}
-\pi, & \pi
\end{array}\right] \text {, }
$$

where $\mathfrak{I}$ and $\mathfrak{R}$ are the imaginary and real parts of the smoothed cross-wavelet transform, respectively.

\footnotetext{
${ }^{3}$ Without smoothing, the squared wavelet coherence would always equal 1 at any frequency and time. Smoothing is achieved by convolution in time and frequency; see Torrence and Compo (1998) for details.
} 
A phase difference of zero indicates that the two underlying series move together while a phase difference of $\pi(-\pi)$ implies that they move in the opposite direction. If $\phi_{x y} \in(0, \pi / 2)$, then the series move in phase (positively co-move) with $x(t)$ leading $y(t)$. If $\phi_{x y} \in(\pi / 2, \pi)$, then the series move out of phase (negatively co-move) with $y(t)$ leading $x(t)$. If $\phi_{x y} \in(-\pi,-\pi / 2)$, then the series move out of phase with $x(t)$ leading $y(t)$. If $\phi_{x y} \in(-\pi / 2,0)$, then the series move in phase with $y(t)$ leading $x(t)$. Note that, the phase difference can also indicate causality between $x(t)$ and $y(t)$ in both the time and frequency domains. As a consequence, it dominates the conventional Granger causality test, which assumes that a single causal link holds for the whole sample period as well as at each frequency (Grinsted et al., 2004; Tiwari et al., 2013). For example, if $x(t)$ leads $y(t)$, then it suggests a causal relationship running from $x(t)$ to $y(t)$ at a particular time and frequency.

Given that economic fundamentals could significantly affect both the U.S. real estate and stock markets, we, therefore, hope to eliminate the effects of economic growth to uncover the real co-movement and causality between the two markets. For this purpose, we rely on partial wavelet coherency and partial phase difference extensions of wavelet coherency and phase difference, respectively. According to Aguiar-Conraria and Soares (2013), we can define the squared partial wavelet coherency between $x(t)$ and $y(t)$ after controlling the series $z(t)$ as follows:

$$
R_{x y \mid z}^{2}(\tau, s)=\frac{\left|R_{x y}(\tau, s)-R_{x z}(\tau, s) R_{y z}^{*}(\tau, s)\right|^{2}}{\left(1-\left(R_{x y}(\tau, s)\right)^{2}\right)\left(1-\left(R_{y z}(\tau, s)\right)^{2}\right)},
$$

where $R_{x z}(\tau, s)$ and $R_{y z}(\tau, s)$ indicate the wavelet coherencies between $x(t)$ and $z(t)$ as well as $y(t)$ and $z(t)$, respectively. Accordingly, we can also represent the partial phase difference as follows: 


$$
\phi_{x y \mid z}=\tan ^{-1}\left(\frac{\Im\left(C_{x y \mid z}(\tau, s)\right)}{\Re\left(C_{x y \mid z}(\tau, s)\right)}\right)
$$

where $\mathfrak{I}$ and $\mathfrak{R}$ indicates the imaginary and real parts of the complex partial wavelet coherency $C_{x y \mid z}(\tau, s)$, respectively. The complex partial wavelet coherency, as the name implies, is the complex type of $R_{x y \mid z}(\tau, s)$ before taking the absolute value.

\section{Data and Empirical Results}

We use U.S. annual data ranging from 1890 to 2012. We acquire the real house and stock prices from the online data segment of Robert J. Shiller's website. ${ }^{4}$ The data on gross domestic product at constant 2005 dollars come from the Global financial database. We transform all these real series by taking natural logarithms to correct for potential heteroskedasticity and dimensional differences between the series. Then, we take first-differences of the concerned variables to get year-on-year growth rates of real stock prices, real housing prices, and real GDP. Note that we define the growth rates of real stock prices and real housing prices in this paper as the stock returns and housing returns, respectively.

Figures 1, 2, and 3 report the time series plots and auto-wavelet power spectrums of real stock returns, real housing returns, and real economic growth, respectively. The thick black lines in wavelet power spectrum plots contours designate the 5-percent significance level estimated from Monte Carlo simulations using a phase randomized surrogate series. The regions below the thin black lines are cones of influence (COI) in which edge effects exist. ${ }^{5}$ As mentioned before, we employ the wavelet power spectrum as an indicator of the local

\footnotetext{
${ }^{4}$ http://www.econ.yale.edu/ shiller/data.htm. Note that to generate real house and stock prices, Shiller deflates the corresponding nominal values with the Consumer Price Index (CPI).

${ }^{5}$ Following Torrence and Compo (1998) and Grinsted et al. (2004), the CWT assumes that the time series are cyclical. When transforming and plotting wavelets for the series with finite length, the amplitudes inside the COI drop by a factor $e^{-2}$ due to zero padding at the edge. In addition, the edge effects are inversely proportional to the frequency. Therefore, we must pay special attention not to misread results inside the COI, especially at lower frequencies.
} 
volatility of underlying series.

Figure 1 shows that the U.S. stock returns exhibit high wavelet power across the 3-10 year frequency band during the interwar period. Within this period, the great bull market, which is generally regarded as one of the biggest stock-market bubbles of all time, crashed in 1929 and the stock market fluctuated dramatically until 1939. In the 1970s, the power of stock returns increase, as a result of the severe oil shock in 1973 and 1978. During the 2000s, the high wavelet power across the 6-8 year frequency band corresponds to the recent remarkable boom-bust cycle in the stock market.

Figure 2 indicates that a relatively high wavelet power of the U.S. housing returns exists before the 1950s. Before the World War I, we see high power across the 2-6 year frequency band, as a result of a succession of boom-bust fluctuations in the U.S. housing market during this period. At the end of World War II, the housing returns exhibited rapid growth in the mid-1940s, however subsequently collapsed in 1947. After that, the volatility of housing returns declines significantly, with the exception over the 1970s and 1980s, when the housing returns rose above and fell below zero in the late 1970s and late 1980s. Most recently, the great housing bubble peaked around the beginning of 2006 and finally burst at the end of 2006, contributing the worst housing crash in U.S. history.

Figure 3 shows that U.S. economic growth exhibits high power across the 2-8 year frequency band until the 1950s. The extremely high power at lower frequency between the 1930s and the 1950s corresponds with the "Great Depression" period marked by the deepest and longest-lasting economic downturn in history. After that, the volatility of economic growth declines steadily. Since the 1980s, the volatility decreased significantly at all frequencies, corresponding to the "Great Moderation” (Blanchard and Simon, 2001). As Aguiar-Conraria et al. (2008) find, we also observe that the Great Moderation associates with a secular rather than decadal trend. 
In general, the wavelet power spectrums yield consistent results with the time plots, reflecting several major booms and busts in the U.S. real estate and stock markets within the sample period. Meanwhile, the stock returns also appear to associate with housing returns for several sub-periods. We cannot determine, however, the co-movement and lead-lag relationship, which can indicate causality, between the two markets through the wavelet power spectrums. Therefore, we resort to wavelet coherency and phase difference between the U.S. real housing returns and real stock returns, with the results of estimation shown in Figure $4 .^{6}$ The correlated regions inside the COI and above 10-percent significance level do not provide reliable indications of co-movement and causality.

Figure 4 shows positive and strong co-movement between the U.S. real estate and stock markets. The co-movement, however, does depend on the frequency and is unstable over the period 1890 to 2012. More specifically, from 1903-1910 and 1915-1933, the two markets show an average coherency of 0.8 across the 3-6 year frequency band with an in-phase relation indicated by the phase difference between $-\pi / 2$ and $\pi / 2$, implying a high degree of co-movement despite frequent boom-bust fluctuations in the two markets during these two periods. From 1938-1955, we observe positive co-movement scattered across the 2-10 year frequency band with an average coherency of 0.7. After that, such co-movements appear temporarily around the 3 year frequency band from 1973-1978, when the severe oil prices shock greatly contributed to the U.S. housing market instabilities and the two successive stock-market decreases in 1973 and 1974, as well as from 1984-1991, when the U.S. stock market crashed in 1987 and almost at the same time the housing returns also went through a temporary drop until 1992. Then, in the last decade, we find an increased coherency of 0.9 and an in-phase relationship both at high and low frequencies, meaning that the two markets positively and highly co-move during the financial crisis. These findings

\footnotetext{
${ }^{6}$ We thank Professors Aguiar-Conraria and Soares for providing us the wavelet package to plot the wavelet coherency and phase difference between the U.S. stock returns and housing returns.
} 
support the existence of time- and frequency-varying features in the correlations between the U.S. real estate and stock markets, but prove largely inconsistent with the findings of Ibbotson and Siegel (1984), Hartzell (1986), and Eichholtz and Hartzell (1996), who suggest a single positive or negative co-movement between the U.S. markets for the specified sample periods.

Figure 4 also shows an interesting picture of causality between the U.S. real estate and stock markets. In the 1900s, the stock returns lead the housing returns across the 4-6 year frequency band, suggesting that returns in stock market significantly affect the returns in housing market during this period. On the contrary, from 1915-1933, housing returns lead stock returns at the 3-6 year frequency band, indicating that returns in the housing market affected returns in the stock market. After that, at high frequencies, we see the causal link running from the stock returns to the housing returns repeatedly for several periods 1938-1955, 1973-1976, 1984-1991 and 2000-2004. In the most recent decade, however, we find the reverse causal link from the housing returns to the stock returns both at the 2-4 year frequency band and at the 6-7 year frequency band. This provides evidence that the U.S. housing market significantly affected the stock market over the last ten years, especially for the four-year period 2007-2010. The great housing-bubble burst led to the remarkable stock market crash. Overall, as displayed in Figure 4, substantial time- and frequency-variations do exist in the causal relationship between the real estate and stock market returns, which largely contradicts with Shirvani et al. (2012) as well as Bouchouicha (2013), who suggest a stable causality between the U.S. residential real estate and stock markets holds in the whole sample period.

the fundamentals of economic growth, however, can significantly influence the U.S. real estate and stock markets and, hence, the relationship between the two markets (Quan and Titman, 1999). This implies that the above results estimated by wavelet coherency and phase 
difference without removing the simultaneous effects of economic growth on the two markets may suffer from some inaccuracy. As a result, we further estimate the partial wavelet coherency and partial phase difference with real GDP growth as a control variable to reveal the relationship between the two markets. Figure 5 reports the findings. ${ }^{7}$ Once again, we note that the correlated regions inside the COI and above 10-percent significance level do not provide reliable information on co-movement and causality.

After controlling for real economic growth, Figure 5 shows that the co-movement between the U.S. real estate and stock markets differs substantially from the previous results. From 1905 to 1910, we find a high degree of positive co-movement increases at the 1-2 year frequency band, but decreases at low frequencies, compared to our prior findings. This reveals that within this period the U.S. real estate and stock markets kept strong co-movement over the short term. From 1915-1933, the positive co-movement found previously decreases significantly as well after removing the effects of economic growth, with a contracted correlated region covering only from 1918 to 1922 . We do see an increased and stable co-movement from 1933 to 1948, in contrast with the scattered co-movement over the same period without controlling for economic growth. Moreover, unlike the previous result indicating insignificant and low co-movement at low frequency from the late 1950s to the late 1970s, we now clearly see a high degree of long-term co-movement indicated by the partial wavelet coherency. More interestingly, we see the unusually negative co-movement indicated by the partial phase difference from 1998 to 2002, when the housing market experienced steady growth whereas the stock market slumped and finally crashed in 2000. Moreover, we do not observe any significant co-movement across all frequencies during the most recent financial crisis. This may imply that the U.S. real estate and stock markets actually respond more to economic growth fundamentals, rather than respond significantly to each other

\footnotetext{
7 The partial wavelet coherency and partial phase difference between the U.S. stock returns and housing returns are also estimated using the wavelet package provided by Aguiar-Conraria, L. and Soares, M. J. and we thanks again.
} 
during these years. In other words, the great housing bubble and its bust, as well as the stock market boom and crash in recent decade may depend fundamentally on the business cycle of economic growth.

The causality between the U.S. real estate and stock markets shows distinctive properties after controlling for economic growth. From 1905 to 1910, we see a short-run causality running from stock returns to housing returns, indicating that the stock market leads the housing market in the short run. From 1918 to 1922, the housing returns leads stock returns at the 3-4 year frequency band. however, That lead-lag relationship inverts at lower frequencies, however. From 1932 to 1948, the causality running from housing returns to stock returns becomes relatively stable over the long term, instead of an unstable and even inverse causal relation before controlling for economic growth. Between the late 1950s and the late 1970s, a significant time-variation exists in the causal relationship between the two markets. Before the early 1960s, housing returns lead stock returns; in the later 1960s and 1970s, it lags behind stock returns. During the Great Moderation, we find that the housing market leads the stock market rather than the reverse, which we find when we do not control or economic growth. From 1998 to 2002, the housing returns significantly lead stock returns, resulting in a shift in money from the stock market into housing market.

In sum, whether we control for economic growth or not, the above results provide robust evidence that the co-movement between the U.S. real estate and stock markets indeed varies across frequencies and evolves over time. In the time domain, the two markets generally show positive co-movement between the two markets with the exception from 1998 to 2002 when a high degree of negative co-movement exists. Understanding markets co-movement and further distinguishing between positive and negative co-movement provides important practical information for portfolio managers. Since stocks provide the most convenient investment vehicle with low transaction costs and high liquidity while real 
estate provides a 'bulky’ asset with high transaction costs and low liquidity, homebuyers and investors use the two assets to diversify their portfolios (Lin and Fuerst, 2012). The diversification gain, however, depends on the nature and degree of the two markets co-movement. More specifically, it declines as the co-movement between the two assets become increasingly positive, but becomes important in the presence of low or negative co-movement. As a consequence, we can infer from our findings that a relatively low diversification gain emerges from the diversification of stocks and housing assets in the U.S. over our sample with the exception from 1998 to 2002 when the U.S. stock market dipped and investors accordingly became more active in the housing market.

In the frequency domain, the two markets correlate with each other mainly at lower frequencies (the 2-10 year frequency band) with the exceptions from 1905 to 1910 and 1998 to 2002, when the two markets correlate at high frequencies (i.e., short term). The identification of the co-movement between the markets at different frequencies is clearly pivotal for investors, since it suggests that investors with different investment horizons should pay more attention to the co-movement at corresponding frequencies so as to allocate their assets more effectively. More specifically, if investors prefer the short-term investment horizon, then they should focus on the co-movement at higher frequencies and, hence, the economic factors driving such co-movement. On the other hand, if investors prefer the long-term investment horizon, then they should focus on the co-movement at lower frequencies and the corresponding driving factors (Smith, 2001). As a result, our findings regarding the co-movement between the U.S. real estate and stock markets mainly across lower frequency bands imply that using stocks and real estate to diversify portfolios in the U.S. should focus on a long-term time horizon. In other words, the diversification gains from investing in stocks and real estate will prove more attractive to long-term investors, such as pension funds, insurance companies, and other institutions, rather than short-term investors. 
In addition to information for investment strategies, the above analysis provides further robust evidence of causalities between the U.S. real estate and stock markets by using (partial) phase differences. The causality between the two markets helps policymakers and investors to forecast future performance from one market to the other through two transmission mechanisms, the "wealth effect" and "credit-price effect". The wealth effect means a transmission channel running from the stock market to real estate market. Real estate serves as an investment and consumption good, while stocks do not involve direct consumption (Benjamin et al., 2004). As such, a rise in stock prices and, hence, an unexpected gain in stock returns increases real estate consumptions and prices. The credit-price effect implies that a rise in real estate prices leads to an increase in stock market prices. That is, when real estate serves as collateral, an increase in its value will reduce the cost of borrowing and enable credit-constrained homes and firms to increase consumption and investment, leading to a rise in stock prices.

In this paper, we do not find any stable causality holding for the whole sample period. Rather, the causality findings exhibit substantial time- and frequency-dependence. From the frequency domain, causal effects exist between the U.S. real estate and stock markets generally across lower frequencies (i.e. long term). Thus, market performance forecasts should focus on longer time horizons so as to enhance the forecasting accuracy of investors and policymakers. From the time domain, the time-varying nature in the long-run causalities between the U.S. real estate and stock markets implies structural changes in the two markets. We observe the structural changes, referring to a long-term shift in the relationship between the two markets, intuitively from the partial phase difference at the 4-8 year frequency band in Figure 5(b). Before the mid-1920s, we find for several sub-periods causality running from stock returns to housing returns, indicating the presence of wealth effect. After that, a structural change occurs. The credit-price effect dominates in the U.S. economy until the 
early 1960s, especially from 1932 to 1948 and from the late 1960s when statistically significant effects exist. The wealth effect reappears, however, between the 1960s and the 1970s. Thereafter, we cannot identify any significant structural changes in the causality between the two markets.

\section{Conclusion}

This paper provides fresh new insights into the relationship between the U.S. real estate and stock markets from 1890 to 2012, applying the novel wavelet analysis. That is, since the presence of structural breaks made the result of non-causality between these two asset prices from standard linear Granger causality tests invalid, we need to adopt a time-varying approach. Wavelet analysis allows a simultaneous assessment of co-movement and causality between the two markets in both the time and frequency domains. Given that both the U.S. real estate and stock markets could respond significantly to changes in the fundamentals of economic growth, we also control for the growth rate of GDP to reveal the true relationships between the two markets by means of the partial wavelet coherency and partial phase differences.

We do find that the co-movement between the two markets varies across frequencies and evolves with time. From the time domain, the two markets exhibit positive co-movement over 1890 to 2012 with an exception from 1998 to 2002 when negative co-movement occurs. Therefore, we conclude, in general, that a low diversification gain emerges from combining stocks and housing assets in a portfolio. From the frequency domain, the two markets correlate with each other mainly at lower frequencies with the exceptions from 1905 to 1910 as well as from 1998 to 2002, when the two markets exhibit correlation over the short term. This implies that combining stocks and real estate in a portfolio achieves diversification generally only at the long-term horizon. More specifically, we also find that the co-movement during the recent financial crisis decreased significantly after controlling for economic growth, 
suggesting that the two markets actually respond more to economic growth fundamentals rather than respond significantly to each other during these years.

We do not find any stable causal links between the U.S. real estate and stock markets for the whole sample. Rather, substantial time- and frequency-dependence effects exist. In the frequency domain, the causal effects occur between the two markets generally across lower frequencies (i.e., long term), implying that market performance forecast should focus on a longer time horizon so as to enhance the forecasting accuracy of investors and policymakers. From the time domain, the time-varying features in the long-run causalities between the two markets imply structural changes in the two markets.

\section{References}

Ambrose, B., Ancel, E., Griffiths, M. (1992). The fractal structure of real estate investment trust returns: a search for evidence of market segmentation and nonlinear dependency. Journal of the American Real Estate and Urban Economics Association, 20(1), 25-54.

Aguiar-Conraria, L., Azevedo, N., Soares, M. J. (2008). Using wavelets to decompose the time-frequency effects of monetary policy. Physica A: Statistical Mechanics and its Applications, 387, 2863-2878.

Aguiar-Conraria, L., Soares, M. J. (2011). Oil and the macroeconomy: using wavelets to analyze old issues. Empirical Economics, 40, 645-655.

Aguiar-Conraria, L., Soares, M. J. (2013). The continuous wavelet transform: moving beyond uni- and bivariate analysis, Journal of Economic Surveys, 00 (0), 1-32.

Andrews, D. W. K. (1993) Tests for parameter instability and structural change with unknown change point. Econometrica, 61, 821-856.

Andrews, D. W. K. and Ploberger, W. (1994) Optimal tests when a nuisance parameter is present only under the alternative. Econometrica, 62, 1383-1414.

Aye, G. C., Balcilar, M., and Gupta, R. (forthcoming) Long- and Short-Run Relationships between House and Stock Prices in South Africa: A Nonparametric Approach. Journal of Housing Research.

Blanchard, O., Simon, J. (2001). The long and large decline in U.S. output volatility, Brookings Papers on Economic Activity, 1,135-164. 
Benjamin, J., Chinloy, P., Jud, D. (2004). Why do households concentrate their wealth in housing? Journal of Real Estate Research, 26, 329-344.

Bloomfield, D., McAteer, R., Lites, B., Judge, P., Mathioudakis, M., Keena, F. (2004). Wavelet phase coherence analysis: application to a quiet-sun magnetic element. The Astrophysical Journal, 617, 623-632.

Bouchouicha, R. (2013). Dynamics of real estate markets and stock markets in the US and the UK. Working paper series.

Chen, N. (2001). Asset price fluctuations in Taiwan: evidence from stock and real estate prices 1973 to 1992. Journal of Asian Economics, 12, 215-232.

Case, K. E., Quigley, J. M., Shiller, R. J. (2005). Comparing wealth effects: the stock market versus the housing market. Advances in Macroeconomics, 5(1), 1-32.

Eichholtz, P. M., Hartzell, D. J. (1996). Property shares, appraisals and the stock market: an international perspective. The Journal of Real Estate Finance and Economics, 12(2), 163-178.

Grossman, A., Morlet, J. (1984). Decomposition of Hardy functions into square integral wavelets of constant shape. SIAM J. Math. Anal., 15 (4), 723-736.

Geltner, D. (1990). Return risk and cash flow with long term riskless leases in commercial real estate. Journal of the American Real Estate and Urban Economics Association, 18(4), 377-402.

Gyourko, J., Keim, D. (1992). What does the stock market tell us about real estate returns? Journal of the American Real Estate Finance and Urban Economics Association, 20(3), 457-486.

Goffe, W. (1994). Wavelets in macroeconomics: an introduction. In D. Belsley (Ed.), Computational Techniques for Econometrics and Economic Analysis, Kluwer Academic, 137-149.

Grinsted, A., Moore, J. C., Jevrejeva S. (2004). Application of the cross wavelet transform and wavelet coherence to geophysical time series. Nonlinear Process Geophysics, 11, 561-566.

Graham, M., Nikkinen, J. (2011). Co-movement of Finnish and international stock markets: a wavelet analysis. European Journal of Finance, 17, 409-25.

Hansen, B. E. (1992) Tests for parameter instability in regressions with I(1) processes. Journal of Business and Economic Statistics, 10, 321-336.

Hartzell, D. (1986). Real estate in the portfolio, in F. J. Fabozzi, eds., The Institutional Investor: Focus on Investment Management, Ballinger, Cambridge, Massachusetts. 
Hudgins, L., Friehe C., Mayer, M. (1993). Wavelet transforms and atmospheric turbulence. Physical Review Letters, 71 (20), 3279-3282.

Ibbotson, R. G., Siegel, L. B. (1984). Real estate returns: a comparison with other investments. Real Estate Economics, 12(3), 219-242.

Ibrahim, M. H. (2010) House price-stock price relations in Thailand: An empirical analysis. International Journal of Housing Markets and Analysis, 3 (1), 69-82.

Johansen, S. (1988). Statistical analysis of co-integration vectors, Journal of Economic Dynamics and Control, 12, 231-54.

Johansen, S. (1991). Estimation and hypothesis testing of cointegration vectors in Gaussian vector autoregressive models. Econometrica, 59, 1551-1580.

Jorion, P., Schwartz, E. (1986). Integration vs. segmentation in the Canadian stock market”. Journal of Finance, 41(3), 603-616.

Kapopoulos, P., Siokis, F. (2005). Stock and real estate prices in Greece: wealth versus credit-price effect. Applied Economics Letters, 12(2), 125-128.

Liu, C. H., Hartzell, D. J., Greig, W., Grissom, T. V. (1990). The integration of the real estate market and the stock market: some preliminary evidence", Journal of Real Estate Finance and Economics, 3(3), 261-282.

Liow, K. H., Yang, H. S. (2005). Long-term co-memories and short-run adjustment: securitized real estate and stock markets. The Journal of Real Estate Finance and Economics, 31(3), 283-300.

Liow, K. H. (2006). Dynamic relationship between stock and property markets. Applied Financial Economics, 16(5), 371-376.

Liow, H. K. (2012). Co-movements and correlations across Asian securitized real estate and stock markets. Real Estate Economics, 40(1), 97-129.

Lin, P. T., Fuerst, F. (2012). The integration of direct real estate and stock markets in Asia. Working paper series.

Loh, L. (2013). Co-movement of Asia-Pacific with European and US stock market returns: a cross-time-frequency analysis. Research in International Business and Finance, 29, $1-13$.

MacKinnon, J. G., Haug, A. A., and Michelis, L. (1999) Numerical distribution functions of likelihood ratio tests for cointegration. Journal of Applied Econometrics, 14, 563-577.

McMillan, D. (2012). Long-run stock price-house price relation: evidence from an ESTR model. Economics Bulletin, 32(2), 1737-1746. 
McCarthy, J., Orlov, A. G. (2012). Time-frequency analysis of crude oil and S\&P500 futures contracts. Quantitative Finance, 12(12), 1893-1908.

Myer, F. C. N., Webb, J. R. (1993). Return properties of equity REITs, common stocks, and commercial real estate: a comparison. Journal of Real Estate Research, 8(1), 87-106.

Ng, S., Perron, P., 2001. Lag length selection and the construction of unit root tests with good size and power. Econometrica, 69, 1519-1554.

Nyblom J. (1989) Testing for the constancy of parameters over time. Journal of the American Statistical Association, 84, 223-230.

Okunev, J., Wilson, P. J. (1997). Using nonlinear tests to examine integration between real estate and stock markets. Real Estate Economics, 25(3), 487-503.

Okunev, J., Wilson, P., Zurbruegg, R. (2000). The causal relationship between real estate and stock markets. Journal of Real Estate Finance and Economics, 21(3), 251-261.

Phillips, P.C.B. and Hansen, B.E. (1990) Statistical inference in instrumental variables regression with I(1) processes. Review of Economics Studies, 57, 99-125.

Quan, C. D., Titman, S. (1999). Do real estate prices and stock prices move together? An international analysis. Real Estate Economics, 27(2), 183-207.

Ramsey, J., Lampart, C. (1998a). Decomposition of economic relationships by time scale using wavelets: money and income. Macroeconomic Dynamics, 2, 49-71.

Ramsey, J., Lampart, C. (1998b). The decomposition of economic relationships by time scale using wavelets: expenditure and income. Studies in Nonlinear Dynamics and Econometrics, 3, 23-42.

Rua, A., Nunes, L. C. (2009). International co-movement of stock market returns: a wavelet analysis. Journal of Empirical Finance, 16, 632-639.

Roueff, F., Sachs, R. (2011). Locally stationary long memory estimation. Stochastic Processes and their Applications, 121(4), 813-844.

Shukur, G. and Mantalos , P. (1997) Tests for Granger causality in integrated-cointegrated VAR systems. Working paper 1998:1, Department of Statistics, University of Lund, Sweden.

Sim, S. H., Chang, B. K. (2006). Stock and real estate markets in Korea: wealth or credit-price effect. Journal of Economic Research, 11, 99-122.

Su, C. W. (2011). Non-linear causality between the stock and real estate markets of Western European countries: evidence from rank tests. Economic Modelling, 28, 845-851. 
Su, C. W., Chang, H. L., Zhu, M. N. (2011). A non-linear model of causality between the stock and real estate markets of European countries. Romanian Journal of Economic Forecasting, 1, 41-53.

Shirvani, H., Mirshab, B., Delcoure, N. N. (2012). Stock prices, home prices, and private consumption in the US: Some robust bilateral causality tests. Modern Economy, 3, 145-149.

Torrence, C., Compo, G. (1998). A practical guide to wavelet analysis. Bulletin of the American Meteorological Society, 79, 61-78.

Torrence, C., Webster, P. J. (1999). Interdecadal changes in the ENSO-monsoon system. Journal of Climate, 12(8), 2679-2690.

Tsai, I. C., Lee, C. F., Chiang, M. C. (2012). The asymmetric wealth effect in the US housing and stock markets: evidence from the threshold cointegration model. Journal of Real Estate Finance and Economics, 45, 1005-1020.

Tiwari, A. K., Mutascu, M., Andries, A. M. (2013). Decomposing time-frequency relationship between producer price and consumer price indices in Romania through wavelet analysis. Economic Modelling, 31, 151-159.

Wilson, P., Okunev, J., Ta, G. (1996). Are real estate and securities markets integrated? Some Australian evidence. Journal of Property Valuation and Investment, 14, 7-24.

Worzala, E., Vandell, K. (1993). International direct real estate investments as alternative portfolio assets for institutional investors: an evaluation. The AREUEA conference paper, Anaheim, CA. USA.

Wilson, P., Okunev, J. (1999). Long-term dependencies and long run non-periodic co-cycles: Real estate and stock markets. Journal of Real Estate Research, 18(2), 257-278.

Zhou, J. (2010). Comovement of international real estate securities returns: a wavelet analysis. Journal of Property Research, 27(4), 357-373. 
(a) Stock Returns

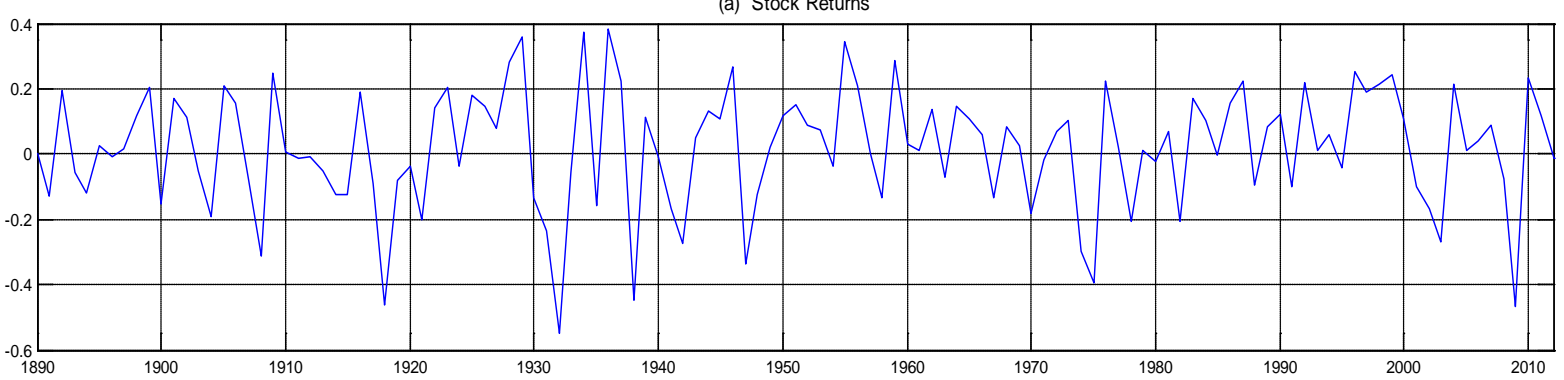

(b) Wavelet Power Spectrum

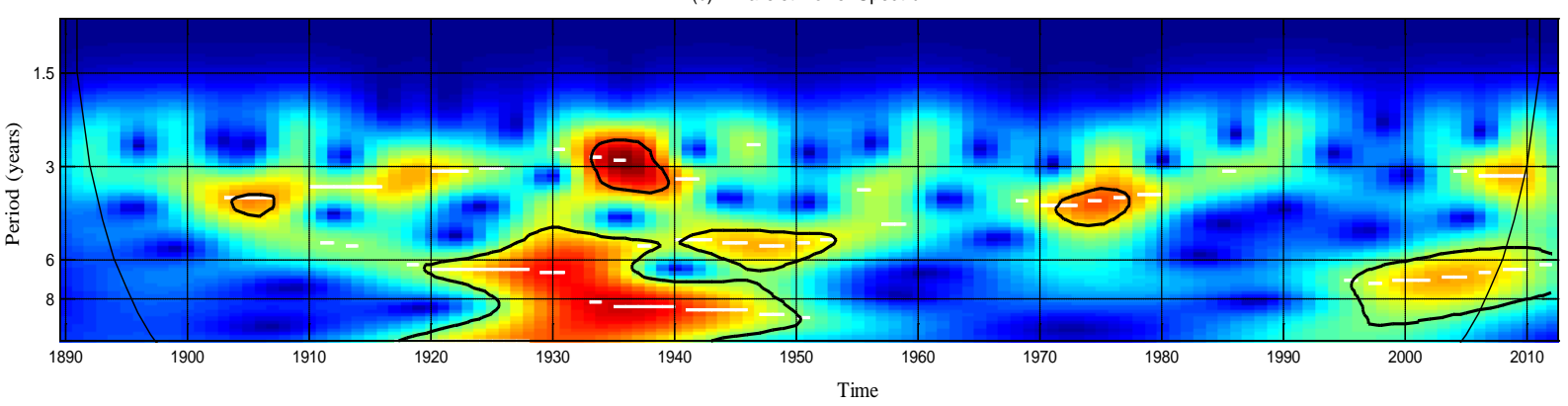

Figure 1: The time series of the U.S. stock returns (a) and its wavelet power spectrum (b). For the wavelet power spectrum, the $y$-axis refers to the frequencies (measured in years); the $x$-axis refers to the time period over the period 1890-2012. The color bar on the right side corresponds to the strength of wavelet power and the local volatility.

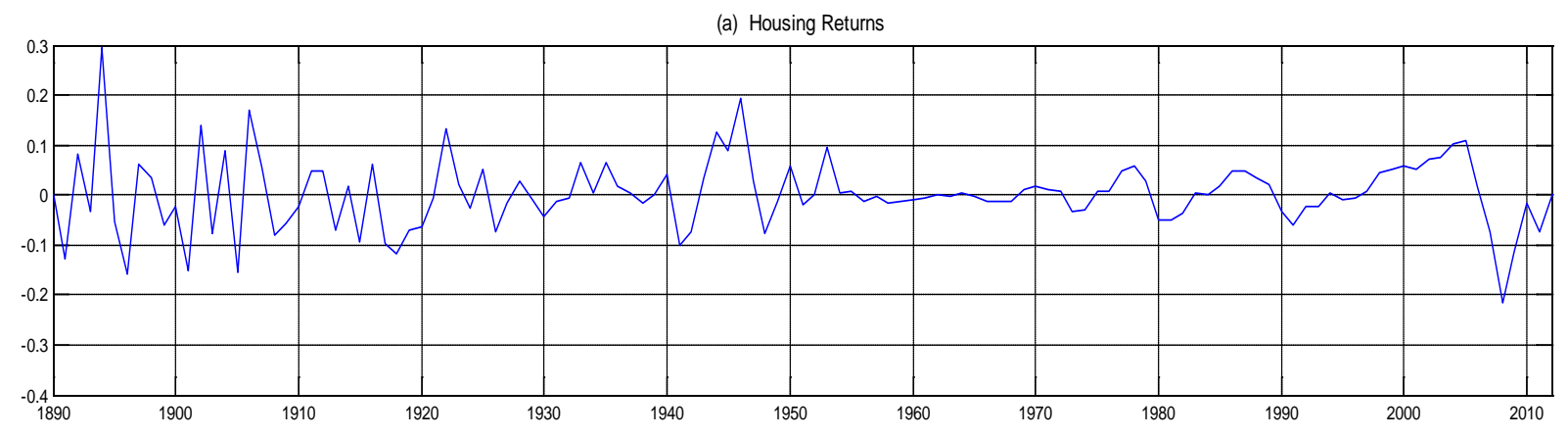

(b) Wavelet Power Spectrum

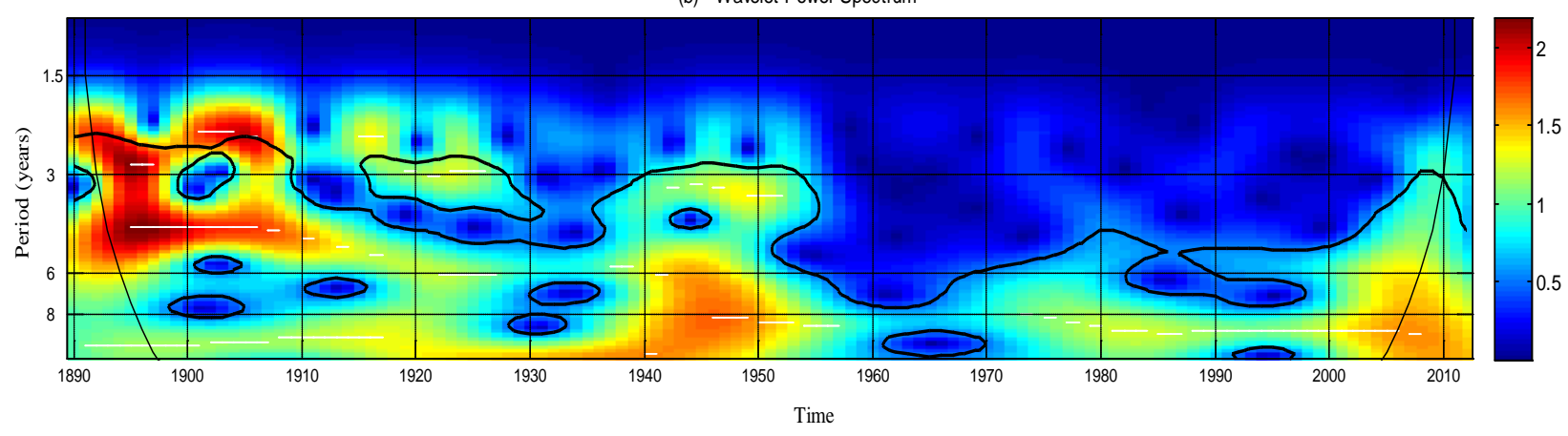

Figure 2: The time series of the U.S. housing returns (a) and its wavelet power spectrum (b). For the wavelet power spectrum, the $y$-axis refers to the frequencies (measured in years); the $\mathrm{x}$-axis refers to the time period over the period 1890-2012. The color bar on the right side corresponds to the strength of wavelet power and the local volatility. 
(a) Economic Growth

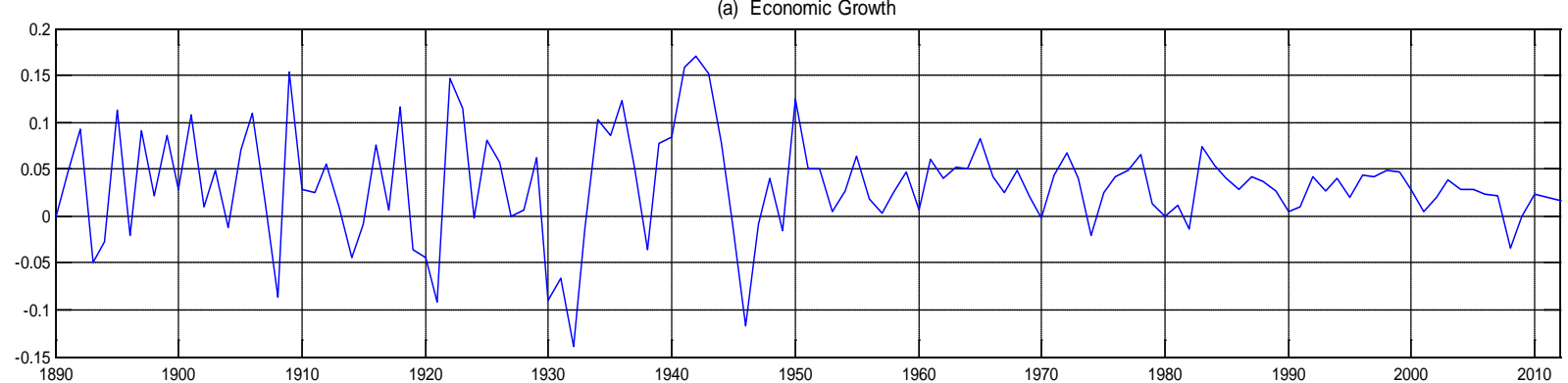

(b) Wavelet Power Spectrum

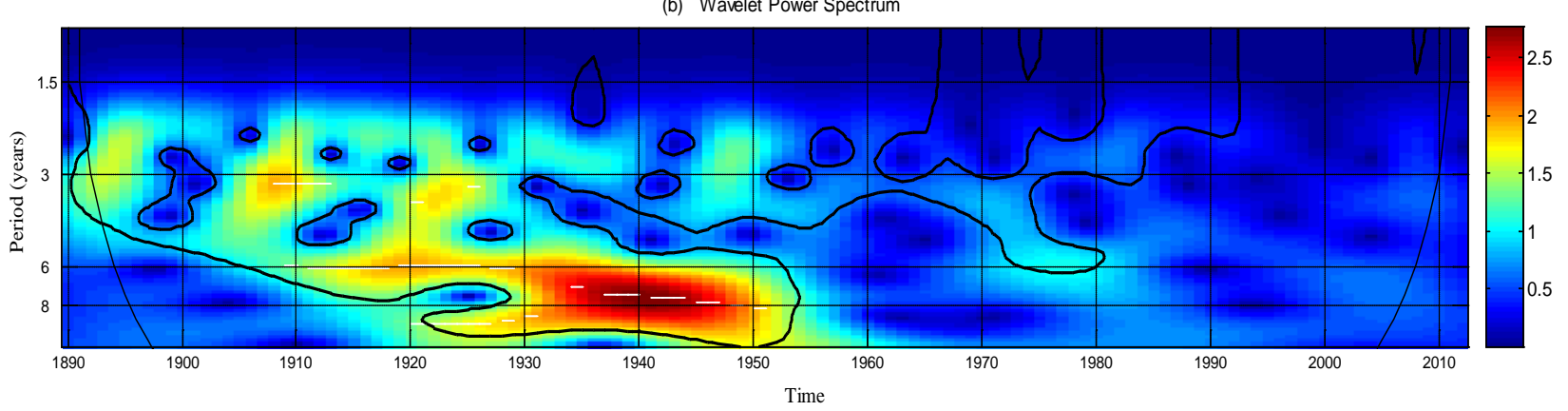

Figure 3: The time series of the U.S. economic growth (a) and its wavelet power spectrum (b). For the wavelet power spectrum, the $y$-axis refers to the frequencies (measured in years); the $x$-axis refers to the time period over the period 1890-2012. The color bar on the right side corresponds to the strength of wavelet power and the local volatility. 

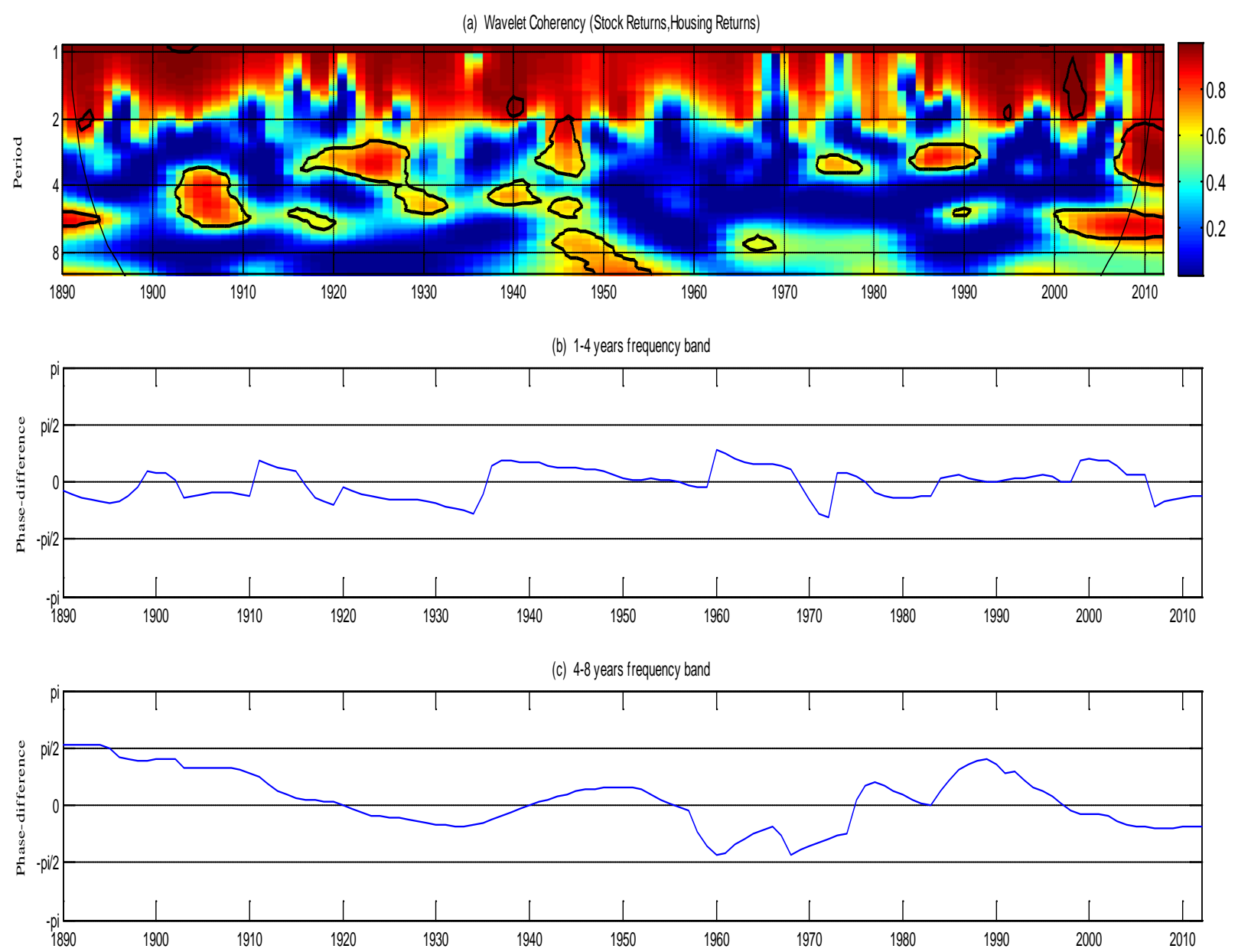

Figure 4: The wavelet coherency (a) and phase difference (b, c) between the U.S. stock returns and housing returns. The $y$-axis refers to the frequencies (measured in years); the $\mathrm{x}$-axis refers to the time period over the period 1890-2012. The color bar on the right side corresponds to the strength of correlation at each frequency. 

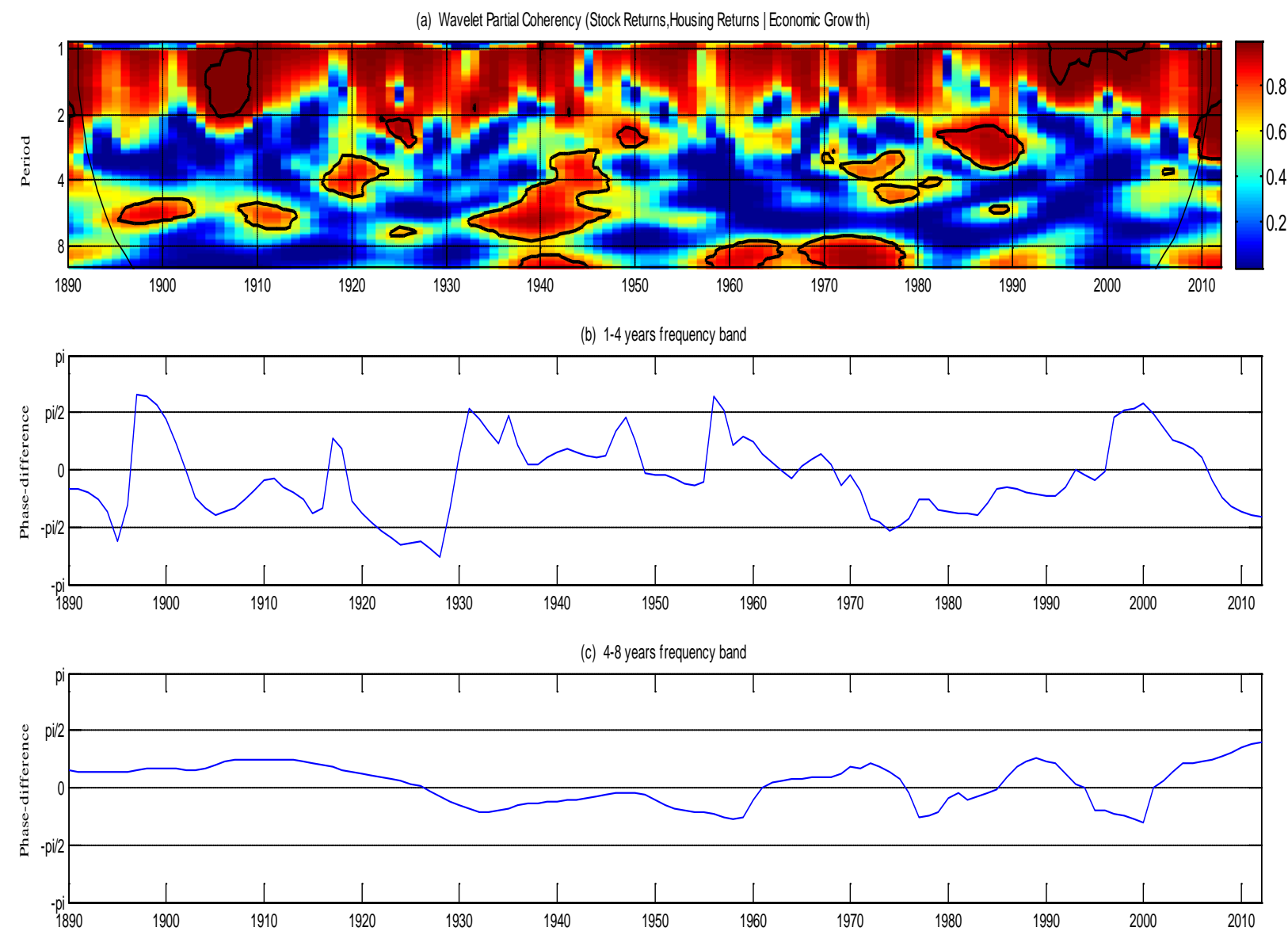

Figure 5: The partial wavelet coherency (a) and partial phase difference $(b, c)$ between the U.S. stock returns and housing returns, with real economic growth as a control variable. The y-axis refers to the frequencies (measured in years); the x-axis refers to the time period over the period 1890-2012. The color bar on the right side corresponds to the strength of correlation at each frequency. 


\section{APPENDIX:}

Table A1: Ng- Perron (2001) $M Z_{a}$ unit root test results

\begin{tabular}{lcccc}
\hline & \multicolumn{2}{c}{ Level } & \multicolumn{2}{c}{ First differences $^{2}$ Series } \\
\cline { 2 - 5 } & (constant) $^{\mathrm{a}}$ & (constant and trend) $^{\mathrm{b}}$ & (constant) $^{\mathrm{a}}$ & (constant and trend) $^{\mathrm{b}}$ \\
\hline LRSPP & -0.57 & -9.80 & $-58.68^{* * *}$ & $-63.13^{* * *}$ \\
LRHP & -7.14 & $-9.94^{*}$ & $-16.76^{* * *}$ & $-33.95^{* * *}$ \\
\hline
\end{tabular}

Notes: LRSP (LRHP) denotes natural log of real stock price (real house price).

${ }^{* * *},{ }^{* *}$, and ${ }^{*}$ indicates significance at the 1-, 5- and 10-percent levels, respectively.

${ }^{a}$ This is a one-side test with the null hypothesis that a unit root exists; 1,5 and 10 percent significance critical value equals to $-13.800,-8.100$, and 5.700 , respectively.

${ }^{\mathrm{b}}$ This is a one-side test with the null hypothesis that a unit root exists; 1,5 and 10 percent critical values equals $-23.800,-17.300,-14.200$, respectively.

\section{Table A 2: Granger Causality Tests}

\begin{tabular}{|c|c|c|c|c|}
\hline \multirow[t]{2}{*}{ Test } & \multicolumn{2}{|c|}{$\begin{array}{c}\mathrm{H}_{0} \text { : Stock Returns do not Granger } \\
\text { cause Housing Returns }\end{array}$} & \multicolumn{2}{|c|}{$\begin{array}{l}\mathrm{H}_{0} \text { : Housing Returns do not Granger } \\
\text { cause Stock Returns }\end{array}$} \\
\hline & Statistic & $p$-value & Statistic & $p$-values \\
\hline Chi-Square Test & 0.4367 & 0.8038 & 2.6333 & 0.3225 \\
\hline Bootstrap $L R$ Test & 1.4592 & 0.2900 & 2.0830 & 0.2390 \\
\hline
\end{tabular}

Notes: Causality tests based on a VAR(2) model, with the lag-length being determined by the Akaike Information Criterion (AIC). Residual-based bootstrap LR causality Tests, as suggested by Shukur and Mantalos (1997), are used to account for small-sample bias.

The null-hypothesis is: No-causal relationship exists between the variables.

Table A3: Multivariate Johansen (1991) Cointegration tests

\begin{tabular}{lcccc}
\hline Series & $\mathrm{H}_{0}{ }^{\mathrm{a}}$ & $\mathrm{H}_{1}$ & Trace Statistic & Maximum Eigen Statistic \\
\hline \multirow{2}{*}{ LRSP and LRHP } & $r=0$ & $r>0$ & 10.95 & 10.58 \\
& $r \leq 1$ & $r>1$ & 0.37 & 0.37 \\
\hline
\end{tabular}

Notes: See Notes to Table A1.

** indicates significance at the 5-percent level.

${ }^{\text {a }}$ One-sided test of the null hypothesis $\left(\mathrm{H}_{0}\right)$ that the variables are not cointegrated against the alternative $\left(\mathrm{H}_{1}\right)$ of at least one cointegrating relationship. The critical values are taken from MacKinnon et al., (1999) with 5-percent critical values equal to 15.49 for testing $r=0$ and 3.84 for testing $r \leq 1$ for the Trace test. The corresponding values for the Maximum Eigenvalue tests are 14.26 and 3.84. 
Table A4: Parameter Stability Tests of the Long-Run Relationship

\begin{tabular}{lcccc}
\hline & Sup-F & Mean-F & Exp-F & \multicolumn{1}{c}{$\boldsymbol{L}_{\boldsymbol{c}}$} \\
\hline LRSP $=\boldsymbol{\alpha}+\boldsymbol{\beta}^{*}$ LRHP & $145.46^{* * *}$ & 68.23 & 68.99 & $10.19^{* * *}$ \\
Bootstrap $\boldsymbol{p}$-value & $<0.01$ & 1.00 & 1.00 & 0.01 \\
\hline
\end{tabular}

Notes: See Notes to Table A1.

The parameter stability tests exhibit non-standard asymptotic distributions. By means of the parametric bootstrap procedure, Andrews (1993) and Andrews and Ploberger (1994) report the critical values and $p$-values for the non-standard asymptotic distributions of these tests. ${ }^{8}$ Besides, according to Andrews (1993), 15-percent trimming from both ends of the sample is required for the Sup-F, Mean-F and Exp-F. Hence, the tests are applied to the fraction of the sample in $(0.15,0.85)$. The $L_{c}$ test proposed by Nyblom (1989) and Hansen (1992) is mainly applied to investigate the long-run parameters stability, with the on the long-run relationship estimated using the Fully Modified ordinary least squares (FM-OLS) estimator of Phillips and Hansen (1990). Particularly when the underlying series are $I$ (1), as is the case shown in Table A1, it also serves as a test of Cointegration.

We calculate $p$-value using 2,000 bootstrap repetitions.

${ }^{* * *}$ indicates significance at the 1 percent level, with the null being stability of parameters.

Table A5: Short-Run Parameter Stability Tests

\begin{tabular}{llccccc}
\hline & \multicolumn{2}{c}{$\begin{array}{c}\text { Real Housing Returns } \\
\text { Equation }\end{array}$} & \multicolumn{2}{c}{$\begin{array}{c}\text { Real Stock Returns } \\
\text { Equation }\end{array}$} & \multicolumn{2}{c}{ VAR (2) System } \\
\cline { 2 - 7 } & Statistics & $\begin{array}{c}\text { Bootstrap } \\
p \text {-value }\end{array}$ & Statistics & $\begin{array}{c}\text { Bootstrap } \\
p \text {-value }\end{array}$ & Statistics & $\begin{array}{l}\text { Bootstrap } \\
p \text {-value }\end{array}$ \\
\hline Sup-F & $58.27^{* * *}$ & $<0.01$ & $20.13^{* * *}$ & $<0.01$ & $46.04^{* * *}$ & $<0.01$ \\
Mean-F & $30.38^{* * *}$ & $<0.01$ & 5.66 & 0.31 & $24.00^{* * *}$ & $<0.01$ \\
Exp-F & $25.06^{* * *}$ & $<0.01$ & $6.71^{* *}$ & 0.03 & $18.69^{* * *}$ & $<0.01$ \\
\hline
\end{tabular}

Notes: See Notes to Table A4.

${ }^{*},{ }^{* *}$ and ${ }^{* * *}$ denote significance at 10-, 5- and 1-percent levels, respectively, with the null being stability of parameters.

\footnotetext{
${ }^{8}$ Specifically, the critical values and $p$-values are obtained using asymptotic distribution constructed by means of Monte Carlo simulations using 2000 samples generated from a VAR model with constant parameters.
} 